\title{
Food and Nutrition Security: Challenges in the New Millennium
}

\author{
P. S. Sharma* and V. S. Prajapati \\ Krishi Vigyan Kendra, Junagadh Agricultural University, Pipalia (Rajkot), Gujarat, India \\ *Corresponding author
}

\section{A B S T R A C T}

\begin{tabular}{|l|}
\hline Ke y w o r d s \\
$\begin{array}{l}\text { Food security, } \\
\text { nutrition, sanitation, } \\
\text { health, hygiene, } \\
\text { malnutrition }\end{array}$ \\
\hline Article Info \\
\hline $\begin{array}{l}\text { Accepted: } \\
\text { 20 May } 2020 \\
\text { Available Online: } \\
\text { 10 June } 2020\end{array}$ \\
\hline
\end{tabular}

India is likely to be the most populous country on the planet by 2030 with 1.6 billion people. It currently accounts for more than $17 \%$ of the global population and 456 million poor or can say $41.6 \%$ living on less than \$ 1.25 a day. Among all problems, nutrition security is the main problem that is embedded within all four of its dimensionsavailability, access, utilization, and stability. This review highlights current food insecurity and nutritional insecurity which are interlinked with each other. This review paper deals with important strategies to improve the nutritional security in India like the promotion of household kitchen gardening, dietary diversification, empowerment of rural women, providing nutrition education, climate change mitigation, use of ICT. The need for a paradigm shift in policy formulation from focusing on food security at the aggregate level to nutrition security at the level of each child and adult implied that the definition 'food and nutrition security' integrates both the conceptual frameworks of food security and nutrition security. This integrated approach aspires not merely to address the micronutrient malnutrition which is a bigger problem than food energy deficiency but is a food-based approach that also tackles non-food factors like water, sanitation, hygiene, and care practices.

\section{Introduction}

There is a consensus about food security definition as Food security exists when all people at all times have physical and economic access to sufficient, safe and nutritious food to meet their dietary needs and food preferences for active and healthy life (FAO 2000). But unfortunately, there is no such common agreement among people about nutritional security definition. One definition suggested is "A Nutritional security is considered nutritional-secure when she or he has a nutritionally adequate diet and the food consumed is biologically utilized such that adequate performance is maintained in growth, resisting or recovering from disease, pregnancy, lactation, and physical work".

In short, there is a big difference, but of course no doubt closes linkage between food security and nutritional security. As nutritional insecurity is the problem through the "Nutritional gap" which is between what foods are consumed and what foods are needed for good nutrition. 
Good health depends on good nutrition. Nutrition is the bridge between agriculture and health. Nutritional security should be achieved through not only with the production of quantity food items but mainly the production of quality food products. Four key dimensions of food security can be identified: availability, access, utilization, and stability. Food availability means the physical existence of a sufficient quantity of food of appropriate quality and is determined by domestic food production, domestic stocks, and food imports. Food access can be achieved through adequate income or resources that allow the purchase or acquisition of appropriate food products for a nutritious diet. However adequate food supply does not necessarily guarantee household or individual level food security, as lack of access to food is often a great problem than availability particularly the most malnourished (World Bank, 2007). As for food utilization, it refers to the process through which the body utilizes various nutrients in the food. It also requires proper food preparation and hygiene practices, sound eating habits, a diverse diet which necessitates the availability of all essential nutrients, and proper intra-household distribution of food. By ensuring sufficient calorie and nutrient intake as well as safe food, food utilization may significantly influence the nutritional status of individuals. Finally, the last dimension of food stability strives to secure the dimensions of food availability, access, and utilization over time. For example, access to food should remain unaffected even during sudden shocks such as war, climate events, or economic crises. Ultimately, to achieve food security, all four dimensions must be fulfilled simultaneously.

There is a great alarming need to secure access to an appropriately nutritious diet, comprising all essential nutrients and water, coupled with a sanitary environment and adequate health services and care to ensure a healthy and active life for all household members has been defined by the Food and Agriculture Organization (FAO) as nutritional security, hence emphasizing the health component and nutritional status of the individual or community (FAO, 2012). The relationship between food security and nutrition security is complex, as illustrated by the malnutrition outcomes of overweight and obesity. Malnutrition which is the world's most serious health problem consists of under nutrition, imbalances, and over nutrition and it is the single biggest contributor to a child's mortality. Data reveal that obesity is more prevalent in food-insecure populations for multiple reasons. For example, a lack of adequate resources for healthy food can result in weight gain through several channels. Lowincome families may seek to maximize their limited incomes by consuming low-cost, energy-dense foods, instead of more expensive, nutrient-dense foods (Darmon et $a l ., 2002)$. Concerning India, India is likely to be the most populous country in the world by 2030 with 1.6 billion people. It currently accounts for more than $17 \%$ of the global population and unfortunately 456 million or $41.6 \%$ living on less than $\$ 125$ a day (Chen and Ravallion, 2008). Hence it suggests that nutrition security is the only solution to solve malnutrition and health issues. But about $75 \%$ of India's poor and hungry live in rural areas and depend on agriculture as their primary source of food, employment, and income (FAO, 2009 b).

So, to tackle the widespread problem of nutrition, it might be necessary to move to scale up "nutrition-sensitive intervention" that addresses the underlying causes of under nutrition. We can say that food security cannot be achieved without nutrition security and vice versa. Human needs can only be satisfied through a diversity of macro and micronutrients to ensure good health and 
prevention from diseases. Experts have recognized this fundamental connection and are increasingly using the term food security and nutrition security, which merges both the concepts to emphasize both the food and health requirements for populations (Weingartner, 2005).

\section{Problems of nutritional insecurity in India}

Nutritional insecurity is a nutrition gap that is between what foods are consumed and what foods are needed for good nutrition. Even if there is availability as well as access to food, there is no guarantee of adequate absorption or nutrition, especially since nutrition depends on many other factors such as the condition of pregnant women, breastfeeding, health factors, hygiene, drinking water, sanitation, etc.

And so access to health care and sanitation facilities is among the key determinants of nutritional security. India's economic growth is good no doubt but the problem of persistent and widespread under nutrition, poverty, and rising inequalities also increasing in absolute quantities (Dreze and Sen, 2013).

Hence economic growth alone cannot deliver nutritional security; rather it requires specific interventions to address nutritional problems through 'nutrition-sensitive', food, and agriculture protection for promoting food and nutrition security. Indeed, improvement in production technology, processing, and transportation have helped to make food more available, however, the accessibility and quality of food consumed by the population have received a little bit less attention, leaving initiatives to tackle nutrition security.

As a result, diets have become less diverse and less nutritious with perversely negative impacts on human health. Good health depends on good nutrition.
Good nutrition in turn depends on agriculture to provide the foods- cereals, pulses, vegetables, fruits, fish, milk, and dairy products- for a balanced diet that meets our needs for energy, protein, vitamins, and minerals. Nutrition security should be achieved through much more attention that needs to be given especially among lowincome rural households, where there is a monotonous daily diet pattern that is high in starchy staple and low in micro and macronutrients lacks "Hidden Hunger" and hence Nutritionally Insecure.

\section{Strategies to improve nutritional security in India}

\section{Food-based strategies for improving nutrition}

Industrial fortified product promotion is one of the comprehensive strategies to achieve nutritional security for eg. Iodized salt and fortified flour. Iron (Fe), Zinc ( $\mathrm{Zn})$, and Vitamin A (VA) are among the most critical micronutrients identified by WHO as most lacking in the diets of the poor. So, through improved plant breeding and agronomic practices, we can achieve nutrition security especially among the poor. For eg. Improved variety of orange-fleshed sweet potatoes and golden rice are very rich in beta carotene (FAO, 2011 a).

\section{Household nutrition garden}

Households with backyard area and with members having an incidence of anemia and Vitamin A deficiency were particularly targeted for cultivating nutrient-rich vegetables and fruits. It supports a significantly higher intake of fresh vegetables, eggs, and milk. Improved nutritional status of mothers is associated with better child health and survival especially in the stages of life like pregnancy and lactating period. 
Empowering women to become effective players

Rural women are the strongest link between agriculture and nutrition. There is a strong link between rural women's empowerment and nutritional security. The men themselves concluded that women were contributing roughly $50 \%$ of the labor and that $50 \%$ of the wages paid for the work should legitimately be paid to the women and her health instead of the entire wage money being paid to the men simply because they are the owners.

This inequality between women and men is greatest and hence women's health and family nutritional status are poorest. If women and men had equal status, the prevalence of underweight children would decline by almost 30 percent (Jose and Navaneetham, 2010). Strengthening women's position both within the agricultural sector and within the household can significantly improve household nutrition and health (Fan and Pandya 2012).

\section{Strengthening links between the agriculture, nutrition and health sectors}

There should be a combined effort by public health, nutrition education, and dietary strategies. Food-based interventions will be more effective when accompanied by community health programs and primary health centers.

\section{Providing nutrition education}

Interventions should include a strong program of nutrition education and behavior change targeted principally towards women and adolescent girls to ensure that increases in food supply and income lead to improved household nutrition. It can be achieved through some programs of food transfer like the Public distribution system and other supplementary nutrition programs like ICDS, Anganwadi centers.

\section{Climate change mitigation}

Climate change and its impact on agriculture are the most emerging issues in food security. The adverse impact of climate change in the form of declining rainfall and rising temperatures, and thus increased severity of drought and flooding, is bound to threaten food security and livelihoods in the economy.

\section{Groundwater improvement improves the nutritional security}

Food Security is greatly threatened by the effects of declining water resources although having great food availability. It is interesting to observe that Gujarat has invested in more than 100,000 check dams through the involvement of non-government organizations since the year 2000 and has been instrumental in recharging water tables. This idea has given rich dividends to Gujarat, which has registered the highest rates of growth in agriculture (above 9\% per annum) among all states of India supportive of the decentralized food availability and nutritional security.

\section{Dietary diversification}

The most sustainable approach for subsistence farming households is diversification of their food production through the introduction of horticultural crops, fish, and livestock that are suited to local agro-ecological conditions and can fulfill micro and micronutrient deficiencies in the local diet. Therefore, foodbased nutrition interventions such as family and community gardens and farms increased the supply and consumption of complementary foods such as roots, tubers, legumes, fruits and vegetables, products of animal origin, medicinal plants, spices, and others. 
These during the whole year round, resulting in food reserves that can be stored and processed and any surplus sold thus contributing to the household economy.

\section{Use of ICT}

Awareness creation about the problem of nutrition and the need for a diversified diet is essential for the change in the dietary habit of the consumers and the production pattern of the farmers. In this scenario, ICT can play an important role right from the production to marketing for the farmers and the price, information, and awareness among the consumers.

\section{Sanitation through improve nutrition and food security}

This year our country focused on all possible ways to improve rather dense positive efforts to convert food security into nutrition security. But we cannot forget the link between food security, sanitation, and nutrition security as no food and nutrition security is possible without improved water, sanitation, and hygiene (WASH).

Although there is some progress towards greater policy coherence in this area, a lot more needs to be done on policy and implementation levels to make sure WASH is part of the solution to under nutrition. Access to safe drinking water, sanitation, and hygiene (WASH) services is a fundamental element of healthy communities and has an important positive impact on nutrition.

The international humanitarian organization Action Against Hunger has published a new guidebook for improving nutrition through the integration of water, sanitation, and hygiene (WASH) and nutrition interventions (UNICEF 2017). The "WASH' Nutrition Practical Guidebook," funded by the
European Commission via EU Civil Protection and Humanitarian Aid Operations (DG ECHO), combines expertise from many individuals and organizations working in WASH, health, and nutrition, including the United Nations Children's Investment Fund (UNICEF), the World Health Organization (WHO), Action Against Hunger, Water Aid, Concern Worldwide and more.

While the importance of water, sanitation, and hygiene as a determinant of under nutrition is well understood, translating this into integrated approaches is a real challenge. By compiling concrete programmatic examples in a variety of contexts, this manual guides how WASH activities can contribute to the reduction of under nutrition incidence, and also to the optimization of its treatment," said Marie-Sophie Whitney, a global nutrition expert with the EU Civil Protection and Humanitarian Aid Operations.

This WASH document is organized into the following sub-topics

Provides a brief overview of the evidence on nutritional gains associated with WASH interventions and existing global commitments for joint WASH and nutrition actions.

Describes key WASH practices that can be included in nutrition programs.

Describes practical actions and how to integrate WASH into nutrition activities through delivery channels at the community and household levels.

Proposes an M\&E framework, including a set of indicators to measure progress and improve integrated implementation activities.

Documents a series of case studies on the activities, successes, and challenges from programs that have integrated WASH and nutrition. 


\section{Water, Sanitation, and hygiene}

\section{Water}

An estimated 663 million people worldwide do not have access to an improved drinkingwater source (UNICEF/WHO, 2015), and an estimated 1.9 billion people rely on drinkingwater that is faecally contaminated (Bain et al., 2014). Improved water sources that are not operated or maintained properly may deliver water that is microbiologically contaminated (WHO/UNICEF, 2011). Besides, microbial recontamination often occurs during the collection of water at the source, transport, and storage within the home (Wright, Gundry \& Conroy, 2004).

\section{Sanitation}

An estimated 2.4 billion people or one-third of the world's population, lack access to an improved sanitation facility, and $13 \%$ practice open defecation. Among the world's regions, sub-Saharan Africa and South Asia continue to have the lowest sanitation coverage (WHO/UNICEF, 2015).

\section{Hygiene}

Unlike household access to drinking water and sanitation, no global mechanism exists to monitor hand washing practices in homes and communities. Furthermore, it is difficult to obtain reliable global estimates on hand washing with soap. However, in a recent systematic review of 42 studies of observed hand washing with soap in 19 countries, it was estimated that only $19 \%$ of people worldwide wash their hands after potential contact with excreta (Freeman et al., 2014). Despite indications of their importance for health and nutrition, few rigorous data exist on food and environmental hygiene practices. Food and Nutrition security is an ongoing challenge for the present scenario. There is a clear need for expanded and updated data covering the multiple dimensions of food and nutrition security, to support evidence-based policies and programs. Efforts should also be undertaken to explore the potential importance of nutrition security. Poverty and malnutrition are the outcomes of complex interaction and interplay of factors and actors in the food environment.

Agricultural policy has been considered as the important pathways for reducing malnutrition in the country. There should be a strong strengthening of the links between the agriculture, nutrition, and health sectors. All public policies and efforts of all economic actors/agents must focus on safe, clean, and green nutritious food for the nutritional security of the country. Therefore, generating reliable and comprehensive data and information around food and nutrition security and building capacity will be essential to provide the right abilities and processes for evidence-based decisions to address this challenge now and into the future.

\section{References}

Bain R, Cronk R, Hossain R, Bonjour S, Onda K, Wright J et al., (2014). Global assessment of exposure to faecal contamination through drinking water based on a systematic review. Trop Med Int Health. 19(8):917-27.

Chen S and Ravallion M (2008). The developing world is poorer than we thought, but no less successful in the fight against poverty. Policy Research Working paper 4703. August. The World Bank group, Washington, DC.

Darmon N, Ferguson EL, Briend A. 2002. A cost constraint alone has adverse effects on food selection and nutrient density: an analysis of human diets by linear programming. J Nutr. 132:3764-3771. 
Dreze J and Sen A. (2013) An uncertain glory: India and its contradictions. Princeton University Press. Princeton, New Jersey Government of India.

Fan S and Pandya -Lorch R (2012) Reshaping agriculture for nutrition and health. An IFPRI 2020 Book. Pp. 1-10

FAO (2011a). Combating micronutrient deficiencies: Food-based approaches, by B Thompson \& L. Amoroso, eds. Rome, FAO and Wallingford, UK, CABI

FAO (2009b). How to feed the world in 2050? Rome.

Food and Agricultural Organization. 2012. The state of food insecurity in the world: economic growth is necessary but not sufficient to accelerate reduction of hunger and malnutrition. Rome, Italy.

Food and Agriculture Organization of the United Nations. Global forest resources assessment 2000(Online available from http;/www.fao.org/docrep/004/y1997e/y 1997e00.html)

Freeman MC, Stocks ME, Cumming O, Jeandron A, Higgins JP, Wolf $\mathrm{H}$ et al., (2014). Hygiene and health: systematic review of hand washing practices worldwide and update of health effects. Trop Med Int Health. 19(8):906-16.

Jose S and Navaneetham K (2010). Social infrastructure and women under nutrition.

UNICEF (2011). Programming guide: infant and young child feeding. New York (NY):United Nations Children's Fund,
Nutrition Section

(http://www.unicef.org/nutrition/files/Fi nal_IYCF_programming_guide_2011.p df).

UNICEF (2017). Integrating Water, Sanitation, Hygiene and Nutrition to Save Lives. A practical guidebook on increasing nutritional impact through integration of WASH and nutrition programmes

(https://www.actionagainsthunger.org/si tes/default/files/publications/2017_ACF _WASH_NutritionGuidebook_BD.pdf)

UNICEF/WHO (2015). Progress on sanitation and drinking water: 2015 update and MDG assessment. Geneva: United Nations Children's Fund and World Health Organization (http://www.unicef.org/publications/ind ex_82419.html).

Weingartner L. 2005. Paper I. The concept of food and nutrition security. In: Klennert $\mathrm{K}$, editor. Achieving food and nutrition security: actions to meet the global challenge: a training course reader. Feldafing: German Society for International Cooperation; p. 3-28.

World Bank. 2007.World development report 2008: agriculture for development. Washington (DC):

Wright J, Gundry S, Conroy R (2004). Household drinking water in developing countries: a systematic review of microbiological contamination between source and point-of-use. Trop Med Int Health. 9(1):106-17.

\section{How to cite this article:}

Sharma. P. S. and Prajapati. V. S. 2020. Food and Nutrition Security: Challenges in the New Millennium. Int.J.Curr.Microbiol.App.Sci. 9(06): 2893-2899.

doi: https://doi.org/10.20546/ijcmas.2020.906.349 